(C) [2007] IEEE. Reprinted, with permission, from [Mircea Popescu, David G. Dorrell and Dan M. Ionel A Study of the Engineering Calculations for Iron Losses in 3-phase AC Motor Models, Industrial Electronics Society, 2007. IECON 2007. 33rd Annual Conference of the IEEE 5-8 Nov. 2007]. This material is posted here with permission of the IEEE. Such ermission of the IEEE does not in any way imply IEEE endorsement of any of the University of Technology, Sydney's products or services. Internal or personal use of this material is permitted. However, permission to reprint/republish this material for advertising or promotional purposes or for creating new collective works for resale or redistribution must be obtained from the IEEE by writing to pubs-permissions@ieee.org. By choosing to view this document, you agree to all provisions of the copyright laws protecting it 


\title{
A Study of the Engineering Calculations for Iron Losses in 3-phase AC Motor Models
}

\author{
${ }^{+}$Mircea Popescu, ${ }^{+}$David G. Dorrell and ${ }^{\#}$ Dan M. Ionel \\ ${ }^{+}$University of Glasgow, Glasgow, G12 8LT, UK \\ \#A.O. Smith Corp., P.O. Box 245012, Milwaukee WI 53224-9512, USA \\ D.Dorrell@elec.gla.ac.uk
}

\begin{abstract}
This paper presents a study of the practical issues that need to be addressed by the engineering approaches to the incorporation of iron loss calculations into analytical and numerical models of $\mathrm{AC}$ motors. The total iron loss is estimated by summing up different loss components according to the analysed engineering approach. Illustrative examples are used and these are a 3-phase interior permanent magnet (IPM) motor and a 3-phase induction motor. All the models presented are compared with the no-load and loaded conditions test data.
\end{abstract}

Index terms- iron loss, AC motors, hysteresis loss, eddycurrent loss, interior permanent magnet motor, induction motor

\section{INTRODUCTION}

Analytical models of the AC motors use lumped-parameter equivalent circuits. For a fast computation, the parameters often have constant values. Therefore an accurate prediction of the motor performance assumes: a) accurate estimation of the equivalent circuit parameters; b) realistic mathematical modeling of the circuits used to implement behavior and phenomena inside the machine. In this respect estimation of the iron loss, which may greatly influence the motor total loss, has been approached using various modeling techniques over the last few decades. The calculation, measurement and implementation of the iron loss in the equivalent circuit of an $\mathrm{AC}$ motor represents an important and challenging task in the design of an electrical motor.

\section{IRON LOSS MODELING IN BRUSHLESS SYNCHRONOUS MOTORS}

In a synchronous motor the stator iron losses occur in the teeth and in the yoke. The loss is a function of the total flux in the teeth and in the yoke. If we consider that the yoke and most of the teeth carry a flux which is proportional to the stator flux linkage, it appears to be appropriate to connect an equivalent iron loss resistance $R_{c}$ either at the terminals of the motor equivalent circuit, or more correctly inside the stator resistance $R_{s}$ where the voltage across $R_{c}$ would be the total induced voltage in the stator winding. Hence the equivalent $L \mathrm{~d}-\mathrm{q}$ axis circuit in Fig. 1 may be employed [1]. It should be emphasized that the equivalent iron loss resistance $R_{c}$ exhibits different values with frequency variation, or with current (load) and voltage variation (through saturation effects). Also, test data allows the extraction of the sum of the iron loss and stray load losses. Even tests performed at no-load operation will give only estimation for the iron loss. Thus $R_{c}$ is usually computed either empirically, using empirical coefficients, or with finite element analysis.

The mechanical loss is not controllable through electromagnetic design, but the copper loss and iron loss can be minimized either through an optimized design or more expensively through an optimized control strategy (e.g., vector control). If we consider that the total iron loss may be separated into those caused by mutual flux and called iron- loss and those caused by the leakage flux and called stray-load loss, the equivalent circuit ( $T$ d-q axis) in Fig. 2 has to be used [2]. The mutual flux is comprised of magnet flux and flux created by stator current (armature reaction flux). This flux is proportional to the internal or air gap voltage. It follows that a resistor connected across the air gap voltage can represent the iron-loss. For similar reasons, a resistor $R_{s-l}$ placed across the leakage reactance $\omega L_{l s}$ will represent the stray-load losses. Stray-load losses are comprised of several complex components, not just iron-loss due to the leakage flux. Their physical causes are still under debate.
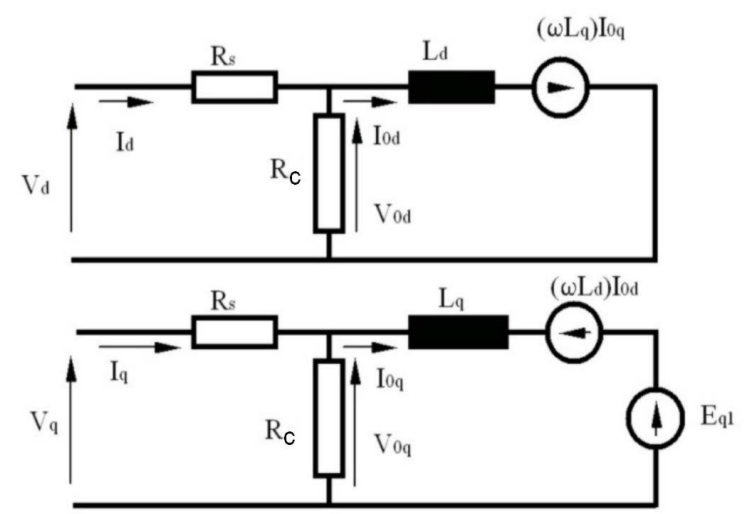

Fig. 1. Equivalent $L \mathrm{~d}-\mathrm{q}$ axis circuit including iron loss.

Another approach [3] is to simulate the iron loss components with two equivalent resistors: one that denotes the voltage dependent losses (similar to a conventional synchronous machine) and one that denotes the current dependent losses. The resistor placed in parallel with the total induced voltage depends on the leakage and magnetization fluxes. This would be similar to the equivalent circuit in Fig. 1, but with the difference that $R_{c}$ takes into account only the so-called voltagedependent iron loss. Actually, the induced voltage due to the magnets determines these losses. The resultant equivalent 
circuit ( $T i \mathrm{~d}-\mathrm{q}$ axis) is illustrated in Fig. 3. All these equivalent circuits may be used for the synchronous motor dynamic and steady-state operation analyses. Note that as at steady-state the synchronous motor operate like a DC machine, the terms $L d i / d t$ are zero.

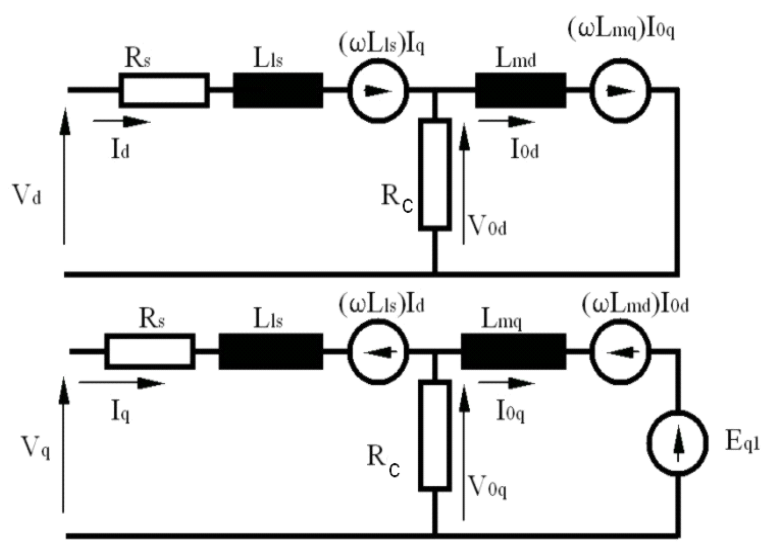

Fig. 2. Equivalent $T$ d-q axis circuit including iron loss.

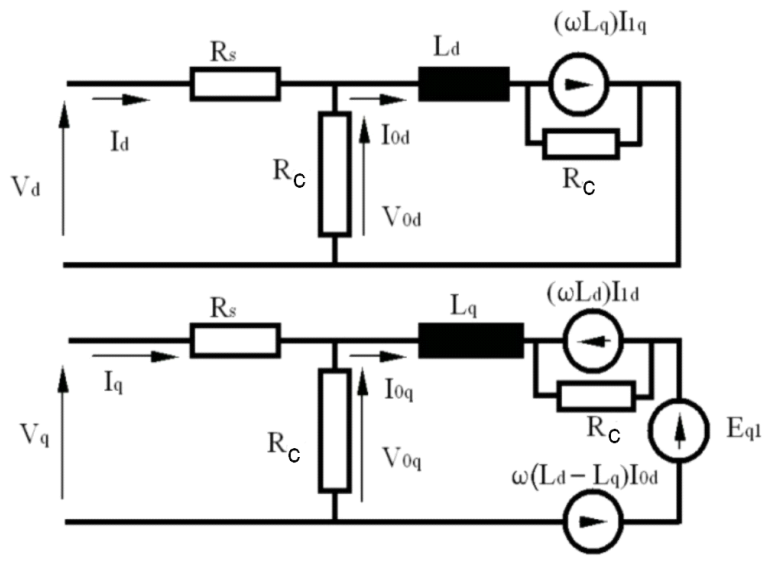

Fig. 3. Equivalent $L$ from $T$ i d-q axis circuit including iron loss.

\section{IRON LOSS MODELING IN INDUCTION MOTORS}

In an equivalent circuit of an induction machine, for linear modeling, the iron of both the stator and rotor is assumed to have negligible reluctance. A considerable increase in torque output can be achieved for a given machine frame by operating at flux density levels where the iron reluctances are significant in comparison with the air gap reluctance. A model that accounts for the iron loss affects, and suitable for various control strategies, is the $L$ model. This has two inductances that can be derived directly from the usual no-load and standstill measurements. The flux densities in the teeth and yoke of the stator are dependent primarily on the total stator flux linkage. Similarly, the flux densities in the rotor iron depend primarily on the net rotor flux linkage. The saturation effect is best modeled as an inductance $L_{s i}$ connected in parallel with the $L$ structure of the motor. A equivalent stator iron-loss resistance, placed exactly in parallel with stator inductance, is used for compactly modeling the iron loss phenomenon. It can be demonstrated that the equivalent iron-loss resistance can express appropriately and independently the eddy-current and hysteresis losses rather than mere vague loss or iron loss. In Fig. 4 it is illustrated that the d-q equivalent circuit for the $L$ model of the induction machine is in an arbitrarily reference frame [11][12]. The equivalent circuit may be used for induction motor transient and the steady-state operation analyses. Note that for cage rotor motors, the rotor voltages $v_{d R}$ and $\mathrm{v}_{\mathrm{qR}}$ are zero.

When rotor flux is chosen to implement an induction motor control system, the most suitable equivalent circuit for implementing the induction motor model is the inverse $L$ model. The effect of stator saturation and iron loss can be included in the inverse $L$ model of equivalent circuit by connecting: (a) the non-linear inductance $L_{s i}$ in parallel with the voltage produced by the rate of change of stator flux linkage; (b) the non-linear resistance $R_{c}$ function of the stator frequency and the flux densities in stator yoke and teeth in parallel with the stator inductance. In Fig. 5 it is illustrated that the equivalent circuit for the $\mathrm{d}-\mathrm{q}$ inverse $L$ model of the induction machine [11][12] is likewise in an arbitrarily reference frame and that this model may be used for induction motor transient and steady-state operation analyses.
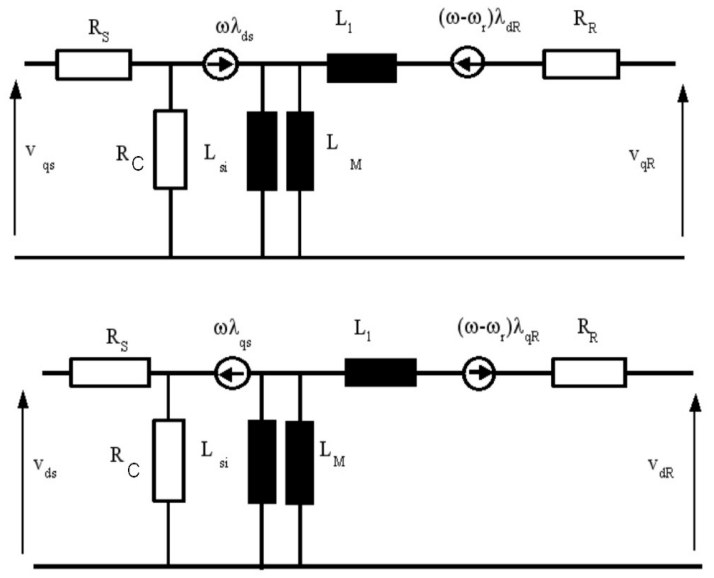

Fig. 4. $d q$ direct $L$ model of the induction motor in arbitrarily reference frame including iron loss.
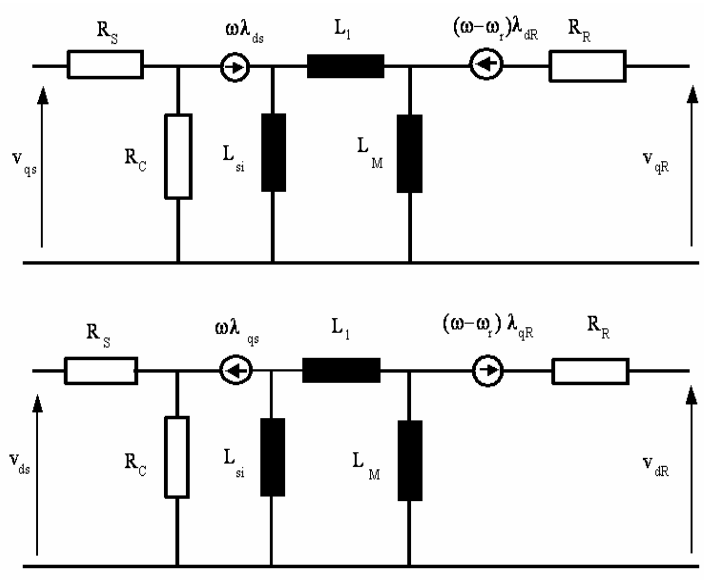

Fig. 5. $d q$ inverse $L$ model of the induction motor in arbitrarily reference frame including iron loss. 


\section{EMPIRICAL METHOdS FOR COMPUTING THE IRON LOSS EQUiVALENT RESISTANCE $\left(R_{C}\right)$}

\section{A. Classical iron-loss method}

Iron loss density data (i.e., $\mathrm{W} / \mathrm{kg}$ ) from steel suppliers is almost always for a sine wave current and may be characterized by the (1) with separate terms for hysteresis, classical and anomalous losses [5][6][15][16][17][23]:

$$
w_{\mathrm{Fe}}=k_{\mathrm{h}} f B^{\alpha}+k_{\mathrm{e}} f^{2} B^{2}+k_{\mathrm{a}} f^{3 / 2} B^{3 / 2}
$$

where $k_{\mathrm{h}} k_{\mathrm{e}} k_{\mathrm{a}}$ are the hysteresis iron-loss, eddy-current ironloss and anomalous iron-loss coefficients, respectively. It is commonly accepted to set $\alpha=2.0$ and ignore the anomalous loss so that the iron loss power density becomes:

$$
w_{\mathrm{Fe}}=f^{2} B^{2} \cdot\left(\frac{k_{\mathrm{h}}}{f}+k_{\mathrm{e}}\right)
$$

\section{B. Modified Steinmetz method}

Another approach is to characterize the iron-loss density variation using (3) with separate terms for hysteresis and eddycurrent losses [7][18]:

$$
w_{\mathrm{Fe}}=k_{\mathrm{h}} f B^{a \cdot B_{P h}+b}+k_{\mathrm{e}} f^{2} B^{2}
$$

hence an average statistical value for the steel permeability and iron-loss would be an appropriate solution. However, this approach requires a large amount of test data for each steel type.

\section{Magnetization curve method}

A simple approach based on the magnetization curve estimation is proposed in this paper. If we consider the $B-H$ curve of the steel as being approximated to

$$
H=B\left(K_{1} e^{K_{2}\left(B_{p k}\right)^{2}}+K_{3}\right)
$$

then the iron loss density is estimated using the expression:

$$
w_{\mathrm{Fe}}=\int_{0}^{B} H d B=\frac{1}{2} \cdot\left[f \frac{K_{1}}{K_{2}}\left(e^{K_{2}\left(B_{p k}\right)^{2}}-1\right)+f^{2} K_{3} B_{p k}^{2}\right]
$$

The exponential term in (5) is associated with the hysteresis loss while the frequency-squared term is associated with eddycurrents loss.

The total iron loss resistance is computed for all empirical methods as [5]

$$
R_{\mathrm{C}}=\left(\frac{V_{0}^{2}}{W_{\mathrm{Fe}}}\right)
$$

where $V_{0}$ represents the induced back EMF and $W_{\mathrm{Fe}}$ is the total iron loss obtained by multiplying $w_{\mathrm{Fe}}$ with the iron weight. The main drawback with the empirical methods is that the coefficient values varies not only with flux density and frequency level, but also depend on the material sample. Figs. 6 and 7 illustrate the variation of the coefficients in (1) or (3) for different magnetization levels or frequency in the same steel lamination. These are for a semi-processed material (M1) or fully-processed material (M2) [14].

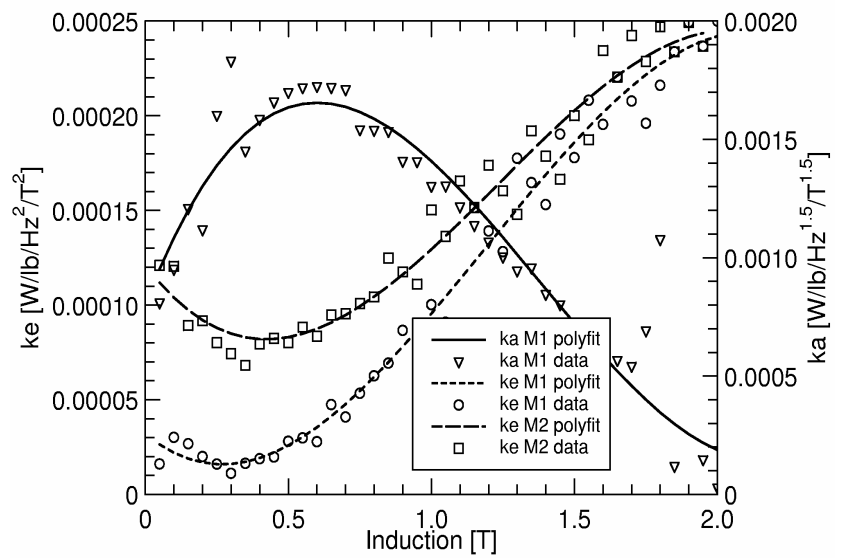

Fig. 6. Eddy-current and excess loss coefficients for a steel sample. Computed values are obtained by polynomial fitting (polyfit in the legend).

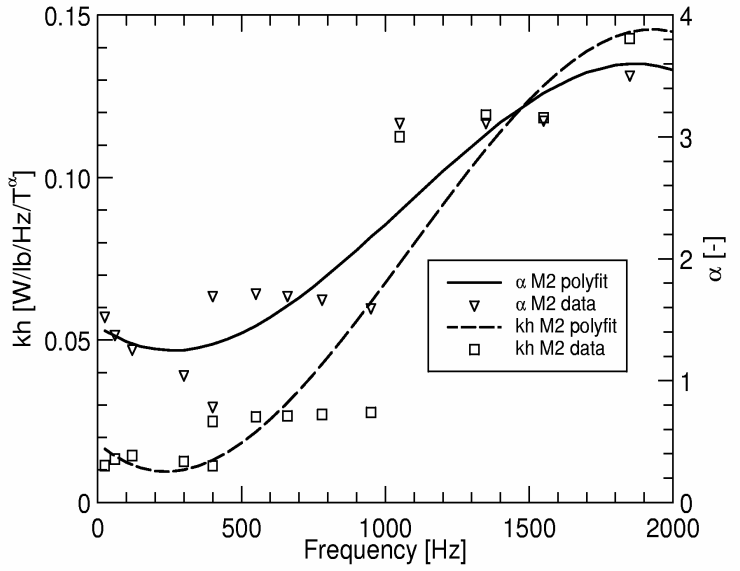

Fig. 7. Hysteresis loss coefficients for a steel sample. Computed values are obtained by polynomial fitting (polyfit in the legend).

\section{Finite Element Method For Computing THE Iron Loss EQUiVALENT RESISTANCE $\left(R_{C}\right)$}

A more accurate option is the use of numerical analysis (e.g., finite elements). If the tooth and yoke flux density waveforms are computed, by using variable loss coefficients we can determine eddy-current loss [14] so that

$$
w_{\mathrm{e}}=\frac{1}{T} \int_{0}^{T} k_{\mathrm{e}}(B)\left(\frac{d B}{d t}\right)^{2} d t=\frac{1}{T} \sum_{i=1}^{N_{\text {step }}} k_{e}\left(B_{i}\right)\left(\frac{B_{i+1}-B_{i}}{\Delta t}\right)^{2} \Delta t
$$

and hysteresis-loss:

$$
w_{\mathrm{h}}=\frac{1}{T} \int_{0}^{T} k_{\mathrm{h}}(f) B^{\alpha(f)} d t=\frac{1}{T} \sum_{i=1}^{N_{\text {sep }}} k_{\mathrm{h}}\left(\frac{1}{T}\right) B_{i}^{\alpha}\left(\frac{1}{T}\right) \Delta t
$$

where numerical integration is employed over one electrical cycle $T$ with $N_{\text {step }}$ samples and $\Delta t$ integration step length.

An alternative for the hysteresis loss expression is to use a constant coefficient $k_{\mathrm{h}}\left(1+k_{\mathrm{eh}}\right)$ that includes the minor loop hysteresis effects [8][9]:

$$
w_{\mathrm{h}}=\frac{k_{\mathrm{h}}\left(1+k_{\mathrm{eh}}\right)}{T} \sum_{i=1}^{N_{\text {step }}} B_{i}^{\alpha}\left(\frac{1}{T}\right) \Delta t
$$


The equivalent correction coefficient that allows the inclusion of the minor loop effects is

$$
k_{\mathrm{eh}}=1+\frac{k}{B_{\mathrm{Max}}} \cdot \frac{\sum_{i=1}^{N_{\text {sepp }}} \Delta B_{i}-4\left[\left|B_{\mathrm{Max}}\right|-\left|B_{\mathrm{Min}}\right|\right]}{2}
$$

where $k$ is a hysteresis loss minor loop constant in the range of 0.6 to $0.7 ; B_{\text {Max,Min }}$ are the maximum and minimum fluxdensities in the airgap for one electrical cycle; and $\Delta B_{i}$ the fluxdensity variation between two consecutive rotor positions. The minor loop effect computed with (10) has the advantage of using the individual flux-density values, rather than the magnitude of the flux density reversals. The total iron loss resistance is computed as

$$
R_{\mathrm{C}}=\left(\frac{V_{0}^{2}}{W_{\mathrm{e}}+W_{\mathrm{h}}}\right)
$$

\section{Simulation AND ExPERimental Results}

Two 3-phase AC motors are analyzed: a $3.5 \mathrm{~kW}$ 6-pole interior PM motor with 36 slots and a distributed winding and a $20 \mathrm{~kW} 60 \mathrm{~Hz} 2$-pole induction motor with 36 slots, 28 bars and a distributed winding. For each tested motor, the iron loss is determined globally through tests and per-component using empirical and numerical methods. The manufacturer used standard Epstein square tests on a large number of steel samples to obtain good steel data.

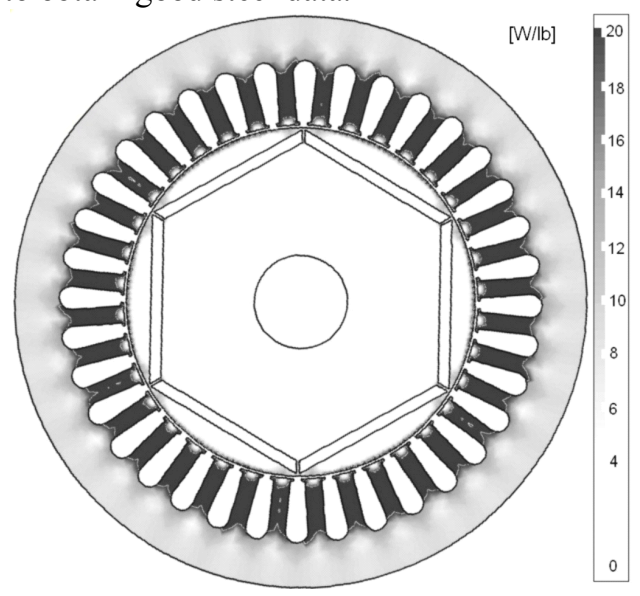

Fig. 8. Cross-sectional view of the analyzed PM motor with total iron loss distribution at no-load.

The motor design examples have been purposely selected to illustrate the strengths of the proposed models and methods. Finite element analysis of the motors allowed iron loss distribution estimation. As previously explained, loss segregation assumes a certain degree of uncertainty. From an engineering point of view, it is important to compare the total iron-loss distribution and also test results against the computed values. For the IPM motor operating in open-circuit (Fig. 8), the flux density in the tooth (the region which accounts for most of the iron loss) is a quasi-square wave (Fig. 9) representing a good test for the capability of the harmonic model to consider the contribution of a large number of harmonics. Additionally, the tangential flux density component is virtually zero and therefore the rotational losses can be neglected. The iron losses in the rotor are very low, making the separation of the measured losses straightforward. Fig. 8 also shows that, for the IPM motor, the iron-losses are located mainly in the stator teeth regions, with high losses concentration in teeth tips. Also, the rotor losses represent a small fraction of the global iron loss and they are located mainly at the rotor surface. This result validates the usual approach that neglects the rotor iron loss in PM motors.

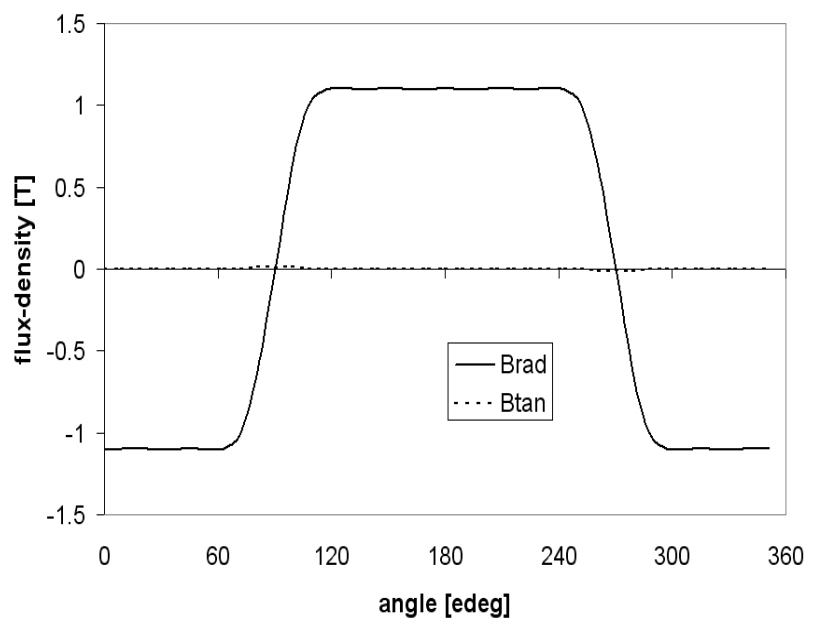

Fig. 9. Radial and tangential flux density variation in the middle of the IPM stator tooth.

Similarly, Fig. 10 presents the total iron loss distribution for the induction motor. The largest fraction of iron-losses occurs in the stator. However, the highest concentration of iron loss dis located in the rotor teeth tips. In an induction motor operating at synchronous no-load, a significant amount of iron losses are produced in the stator yoke, where the flux density has both radial and tangential components (Fig. 11). In particular, at and above rated voltage, this problem is very challenging because of the extremely high value of the flux density.

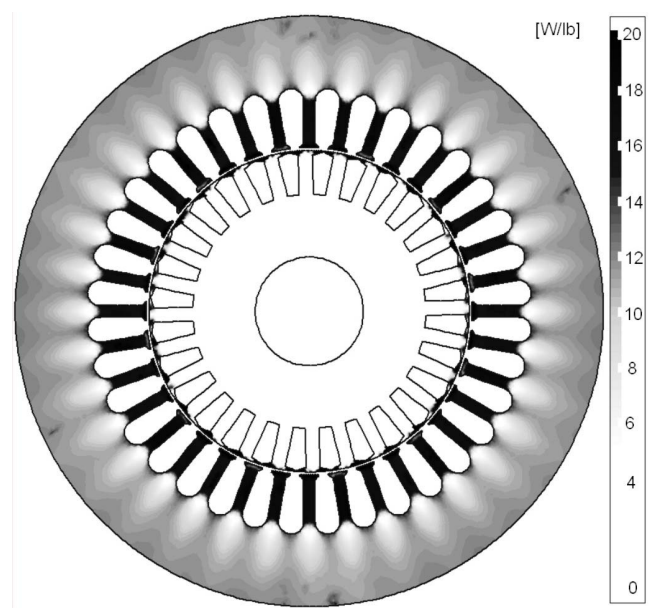

Fig. 10. Cross-sectional view of the analyzed induction motor with total iron loss distribution at no-load. 


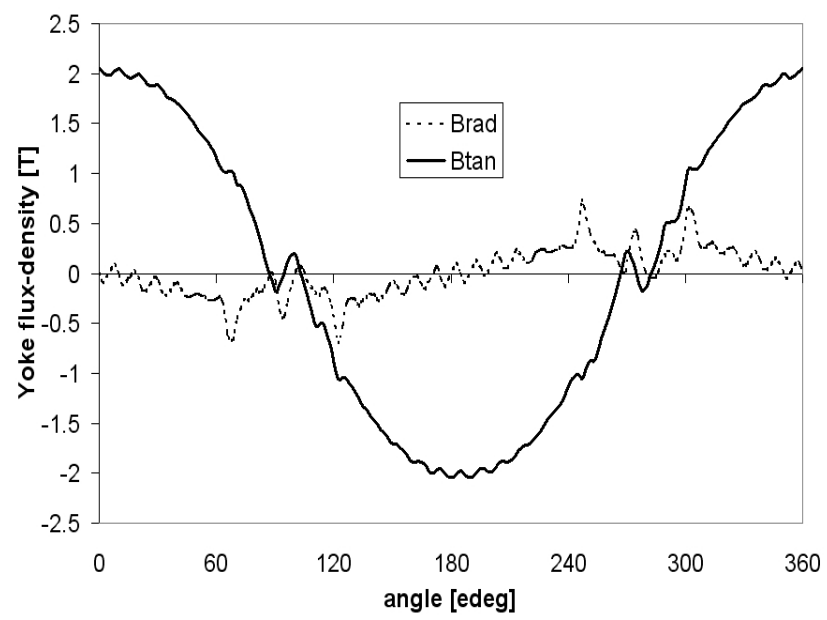

Fig. 11. FE computed flux-density components (radial and tangential) in analyzed induction motor stator yoke.

A no-load test may be performed under varying terminal voltage conditions. The iron loss is defined as the difference between the input power minus the stator copper loss and windage and friction loss. The resultant iron loss is presented in Figs. 12 and 13. Note that for the IPM motor, the no-load iron loss exhibits a minimum at the open circuit voltage and starts to increase if the voltage is decreased beyond this point [3][11]. This behavior is explained through the additional field harmonics that are induced by the armature reaction and/or are a consequence of the PM field.

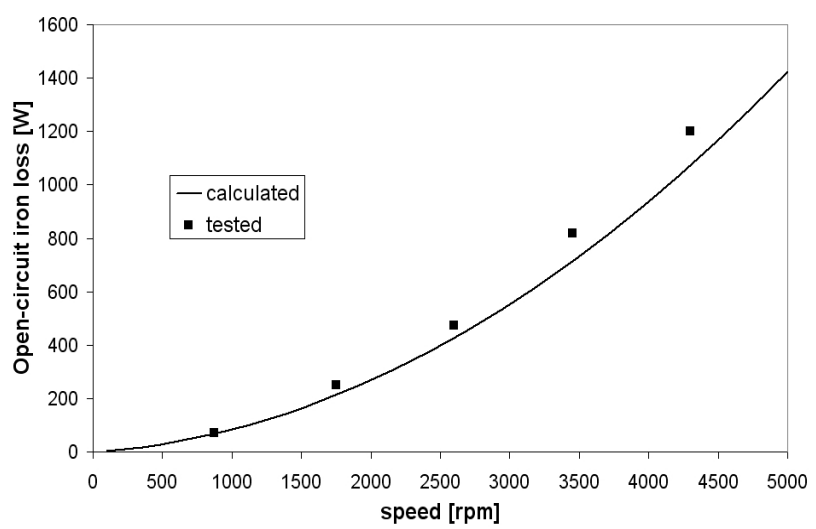

Fig. 12. No-load iron loss variation with voltage for IPM motor.

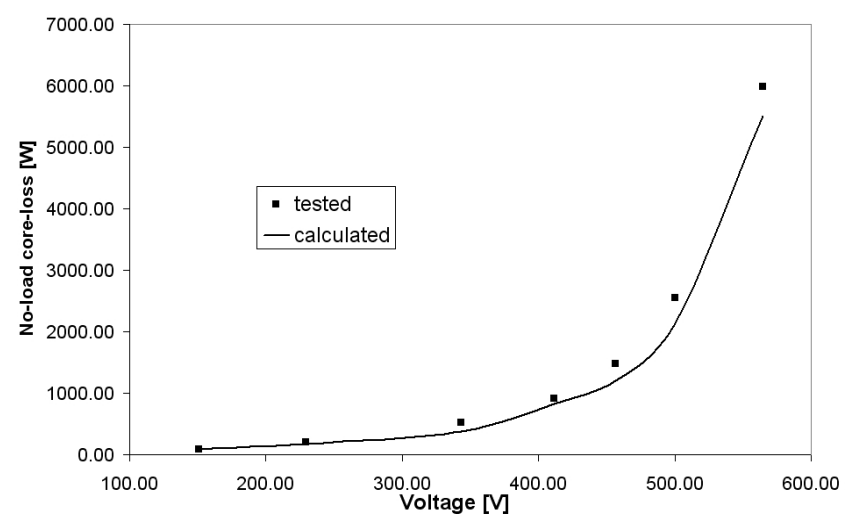

Fig. 13. No-load iron loss variation with voltage for induction motor.
Fig. 14 shows the average torque variation with the load angle for the IPM motor when different equivalent circuits are employed. Note that:

(a) The equivalent circuit described in Fig. 1 predicts a lower electromagnetic torque value for the whole range of the load angle

(b) The equivalent circuit described in Fig. 2 predicts a lower electromagnetic torque value for load angle variation between zero and the load angle corresponding to maximum torque

(c) The equivalent circuit described in Fig. 2 predicts a higher electromagnetic torque value for load angle variation between the load angle corresponding to maximum torque and maximum load angle

(d) The equivalent circuit described in Fig. 3 predicts a higher electromagnetic torque value for load angle variation between zero and the load angle corresponding to maximum torque

(e) The equivalent circuit described in Fig. 3 predicts a lower electromagnetic torque value for load angle variation between the load angle corresponding to maximum torque and maximum load angle

(f) All the equivalent circuits that include iron loss effect predict a lower maximum electromagnetic torque compared to the case when the iron losses are neglected

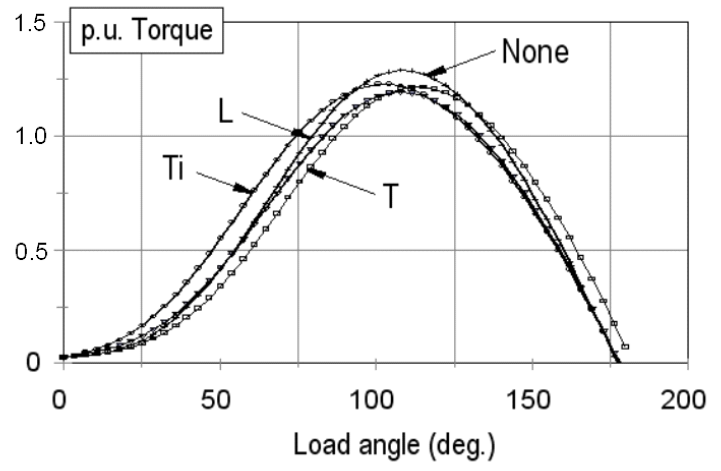

Fig. 14. Illustrative IPM motor torque variation with load angle when iron loss effect is included.

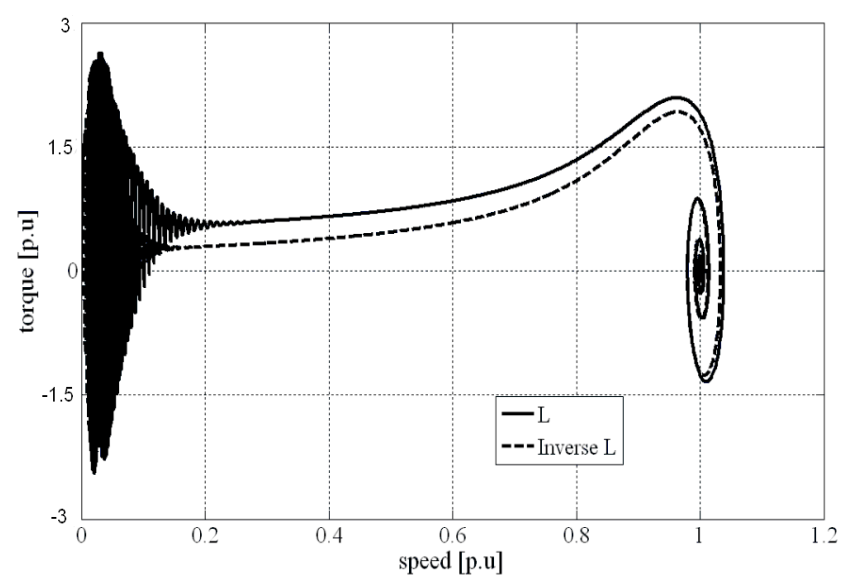

Fig. 15. Illustrative dynamic torque variation with speed for the induction motor when iron loss effect is included. 
Fig. 15 illustrates the dynamic torque variation with speed for the induction motor directly connected to the supply when the equivalent circuits from Figs. 4 and 5 are employed.

The reason for presenting the transient torque behavior is because, from the average torque point of view, there is practically no difference between $L$ and inverse $L$ models at rated speed operation. However, one should note that the $L$ model estimates higher breakdown torque and higher starting torque oscillation. This can have a negative influence on the motor performance when a vector control strategy is employed.

\section{CONCLUSIONS}

The modeling and calculation of the iron loss in 3-phase AC motors can be implemented using different approaches. For some particular rotor configuration - interior PM motor - a significant level of iron loss occurs even at no-load operation if the supply voltage is lower than the induced back EMF. The flux redistribution that occurs due to the strong level of saturation may produce important time harmonic content in the air-gap flux. These harmonics determine additional losses.

The effect of the iron loss can be modeled with sufficient accuracy using fixed value equivalent resistors. The connection of the iron loss resistor in the motor equivalent circuit may be implemented in several ways. One should note that all models have in common the idea of placing the equivalent resistor in the stator circuit. The explanation relies on the fact that in AC motors, the stator iron loss is the main region where the total iron loss does occur. If the estimation of the iron loss resistor is accurate, similar motor performance is predicted with all analyzed models. Iron loss modeling becomes more important when the AC motor is operated at high speed, low flux mode or at variable speed.

For the induction motor the existence of the iron loss in the machine can be included in such manner that solely stator current governs the torque and flux production in the machine. (with equivalent circuit $d-q$ axis fixed parameters, variable values of saturation inductance $L_{s i}$ and an equivalent resistance $R_{C}$. that models the iron loss). The $L$ model may be an option when a stator flux oriented control strategy or scalar control (constant voltage-frequency ratio) is used while the inverse $L$ model may be an option when a rotor flux oriented control strategy is used.

\section{REFERENCES}

[1] [1]. Sebastian, T., Slemon, G.R., Rahman, M.A.: "Modeling of permanent magnet synchronous motors", IEEE Trans. Magnetics, Vol. MAG-22, No.:5, pp. $1069-1071$, Sept. 1986.

[2] Honsinger, V.B. "Performance of polyphase permanent magnet machines", IEEE Trans. Power Appl. Syst., vol. PAS-99, pp.1510-1518, July 1980

[3] Consoli,A., Racitti, A. "Analysis of permanent magnet synchronous motors", Industry Applications, IEEE Transactions on, Volume:27, No: 2, March/April. 1991, pp. $350-354$

[4] Mi, C., Slemon, G.R. Bonert, R.: "Modeling of iron loss of permanentmagnet synchronous motors", IEEE Trans. Industry Applications, Vol. 39, No. 3, May/June 2003. pp. 734 - 741

[5] Bertotti, G., Boglietti, A.A., Chiampi, M., Chiarabaglio, D., Fiorillo, F. "An improved estimation of iron loss in rotation electrical machines" IEEE Trans. Magn.., Vol. 27, pp.5007 - 5009, Nov. 1991

[6] Miller, T.J.E., Rabinovici, R.: "Back-emf waveforms and core losses of brushless DC motors", Proc. IEE - Elect. Power Applicat., Vol. 141, No. 3, pp. 144-154, 1994

[7] Lavers, J.D., Biringer, P.P., Hollitscher, H.: "A simple method of estimating the minor loop hysteresis loss in thin laminations" IEEE Trans. on Magnetics, Vol. 14, No. 5, September 1978, pp. 386 - 388

[8] Deng, F.: "An improved iron loss estimation of permanent magnet brushless machines", IEEE Trans. on Energy Conv., Vol. 14, No. 4, December 1999, pp. 1391-1395

[9] Slemon, G., Liu, X.: "Core losses in permanent magnet motors", IEEE Trans. on Magnetics, Vol. 26, No. 5, September 1990, pp. 1653-1655

[10] Schiferl, R., Lipo, T.A.: "Core loss in buried magnet permanent magnet synchronous motors", IEEE Trans. on Energy Conv. Vol. 4, No. 2. June 1989, pp. $279-284$

[11] Slemon, G.R., "Modelling of induction machines for electric drives", IEEE Transactions on Ind. Appl., Vol. 25,(6), Nov/Dec. 1989, pp. 11261131

[12] Shinnaka, S. "New mathematical models of an induction motor using a minimum number of parameters", Electr. Eng. in Japan, Vol. 126,(2), 1999 , pp. $48-55$

[13] G. Bertotti, "General properties of power losses in soft ferromagnetic materials,” IEEE Trans. Magn., vol. 24, pp. 621-630, Jan. 1988.

[14] D.M. Ionel, M. Popescu, S.J. Dellinger, TJE Miller, R.J. Heideman and M.I. McGilp, "On the Variation with Flux and Frequency of the Core Loss Coefficients in Electrical Machines" -IEEE Transactions on Industry Appl. - Vol. 42, No. 3, May/June 2006, pp. 658-668

[15] M. Amar, R. Kaczmarek "A general formula for prediction of iron loss under nonsinusoidal voltage waveform" IEEE Trans. Magn. Vol. 31, No. 5, September 1995, pp. $2504-2509$

[16]. F. Fiorillo, A. Novikov "An improved approach to power losses in magnetic laminations under nonsinusoidal induction waveform" IEEE Trans. Magn. Vol. 26, No. 5, September 1990, pp. $2904-2910$

[17]. O. Bottauscio, M. Chiampi, A. Manzin and M. Zucca "Additional losses in induction machines under synchronous no-load conditions" IEEE Trans. Magn. Vol. 40, No. 5, September 2004, pp. $3254-3261$

[18]. L. Luk, G.E. Dawson, A.R. Eastham "Finite element and finite difference analysis of losses in laminated material" IEEE Trans. on Magnetics, Vol. 24, No.6, November 1988, pp. 2679-2681

[19]. Atallah, K.; Zhu, Z.Q.; Howe, D "An improved method for predicting iron losses in brushless permanent magnet DC drives"; Magnetics Conference, 1992. Digests of Intermag '92., International , 13-16 April 1992 pp:369-369 